\title{
La Conferencia de Roma sobre no violencia y paz justa en relación con la guerra lícita ${ }^{1}$
}

\author{
ANTONIO COPELLO FACCINI ${ }^{2}$
}

\section{RESUMEN}

Este artículo tiene el propósito de analizar, de forma profunda, por medio de la Filosofía y la Teología, el concepto de la guerra justa, la violencia y la paz. Resulta pertinente este análisis dentro de la coyuntura nacional, ya que muchas ideas han surgido sobre si se justifican o no los conflictos armados. Adicionalmente, el punto principal de este trabajo radica en cómo dichos desarrollos teóricos han tenido incidencia en aquello que se considera lícito o ilícito dentro del ámbito de la guerra. De este modo, cumpliendo con el objetivo en cuestión, se concluye con algunas ideas sobre la búsqueda de la paz y la realidad de la violencia.

Palabras Clave: Violencia, paz, guerra y justicia.

A comienzos del 2016, se reunió en Roma, bajo los auspicios del Consejo Pontificio de Justicia y Paz y Pax Christi Internacional, una conferencia que fue estimulada por el papa Francisco, con participación de expertos religiosos, laicos, teólogos, miembros de congregaciones religiosas, sacerdotes y obispos que viven y trabajan en comunidades y lugares donde se ha experimentado y vivido un clima de violencia y opresión ${ }^{3}$.

1 Fecha de recepción: 7 de junio de 2017. Fecha de aprobación: 14 de junio de 2017. Para citar el artículo: Copellio Faccini, A. (2017). La conferencia de Roma sobre no violencia y paz justa en relación con la guerra lícita, en Revista Con-texto, n. ${ }^{\circ} 47$, pp. 177-189. DOI: https://doi.org/10.18601/01236458.n47.08

2 Doctor en Jurisprudencia y colegial mayor del Rosario. Licenciado en Derecho Canónico de la Universidad Javeriana. Máster en Economía y Administración Pública de Syracuse University. Se especializó en Derecho Comercial y Gerencia Internacional en Italia y en Suiza. Ha sido profesor de Derecho Comercial y Derecho Económico en el Colegio Mayor de Nuestra Señora del Rosario. Fue subsecretario general de la Presidencia de la República y secretario del Consejo de Ministros en la Administración del presidente Alberto Lleras Camargo. Miembro y presidente de la Corte de Arbitraje de la Cámara de Comercio de Bogotá del 2003 al 2005.

3 Francisco De Roux S.J. Columna semanal de El Tiempo, 4 de mayo de 2017. 
La conferencia se pronunció, según sus documentos, en un clima de sufrimiento agudo, trauma y temor vinculado a la militarización. Se trataron temas como las injusticias económicas, el cambio climático y toda una serie de formas específicas de violencia. En este contexto, los participantes que se consideran herederos de la tradición cristiana ${ }^{4}$ llamaron la atención sobre el punto central de la no violencia, sobre la vida y praxis de la Iglesia católica y sobre la vocación de reconciliación y curación de quienes habitan la tierra y de la tierra misma.

Tenemos un historial de experiencias concretas en búsqueda de la paz del mundo entero. Por esta razón, diversos participantes de la conferencia se refirieron a los casos de Uganda y Colombia y al artículo noveno de la cláusula de paz de la Constitución japonesa. Adicionalmente, se enunciaron, como situación especial, los experimentos educativos en las Filipinas para iluminar la creatividad y el poder de las prácticas de no violencia en diferentes situaciones y estadios de actual o potencial conflicto ${ }^{5}$. El anexo de este escrito recoge un texto no oficial de las conclusiones de la conferencia, que se publica con esta salvedad.

Los participantes reconocieron que, en muchas ocasiones de la historia, se ha traicionado este mensaje con su participación en guerras, persecución, opresión, explotación y discriminación. De ahí que ellos no crean en la guerra justa, y piensen que esta teoría se ha utilizado para promover la guerra, en vez de prevenirla.

Parte de esta transformación se deriva de una lectura del magisterio pontificio de la segunda mitad del siglo XX. Por parte del papa san JuAN XXIII, se dijo que la guerra no es un modo apropiado para restablecer el derecho; el papa PABLO VI, quien unió la paz y el desarrollo, dijo en el escenario de las Naciones Unidas: "No más guerra"; san JuAN PABLO II consideraba que la guerra pertenecía a un pasado trágico evidenciado en la historia; por último, BENEDICTO XVI dijo que "amar a los enemigos es el núcleo de la revolución cristiana".

Hace dieciséis siglos, fue el genio de SAN AGUSTín quien estableció los elementos fundamentales de la teoría de la guerra justa, la cual venía de la tradición judeocristiana. Después de él, SANTO TOMÁS y los filósofos y teólogos españoles del Siglo de Oro desarrollaron cabalmente el mismo postulado ${ }^{6}$. Hace ya varios años, en las vísperas de la aventura militar del presidente GEORGE W. BUSH, The Economist encontró relevante regresar

4 Hubiera sido más apropiado, a los cincuenta años del Vaticano II, haber dicho tradición judeocristiana. LAFAYE, JACQUES. Mesías, cruzadas, utopías: el judeo-cristianismo en las sociedades iberoamericanas. 2. ${ }^{\text {a }}$ ed. Fondo de Cultura Económica, 1997.

5 En su propio tiempo, acompañado de una violencia estructural, Jesús proclamó un nuevo y no violento orden fundado en el amor incondicional de Dios, y llamó a sus discípulos a amar a sus enemigos (Mateo $5 ; 44)$, lo cual incluye respetar la imagen de Dios en todas las personas y ofrecer una resistencia sin violencia a quien realiza el mal (MATEO 5; 39); a ser buscadores de la paz, perdonar y arrepentirse, y a vivir en abundancia la misericordia (MATEO 5-7). Jesús estructuró la no violencia por una resistencia vigorosa hacia la deshumanización, como cuando se enfrentó con el precepto del sábado o el poder del templo y, pacíficamente, desafió a los acusadores de una mujer adúltera (JuAN 8; 1-11), o cuando, la víspera de su muerte, pidió a Pedro meter la espada en la vaina (MATEO 26; 52).

6 Santo Tomás de Aquino. Suma de teología. Biblioteca de autores cristianos, 2014. 
al pensamiento de SAN AGUSTín, para poner de presente que la teoría de la guerra justa era inaplicable en estos casos.

"La ética de la guerra

The Economist, Julio 27 de 2006

A medida que la guerra en Líbano avanza, bay varias maneras de bacer un juicio moral:

"Si, Israel tiene derecho a existir y a defenderse, pero el bombardeo de casas, carreteras y servicios públicos y matando a cientos de civiles es sin duda muy fuera de proporción con el delito que sufrió. Pero, ino tiene una diferencia que nuestro enemigo en el Libano, con su arsenal de cobetes de pie a 12.000, quiere destruir nuestro estado? Tenga en cuenta todo eso, y sin duda nuestra respuesta (que está muy por debajo de nuestro potencial y trata de minimizar las muertes de civiles) está restringido: Proporcionales, de becho, a la amenaza que enfrentamos.

Un argumento en sólo esas líneas está pasando entre Israel y sus detractores en el mundo. Ambas partes en el argumento de presumir que la proporcionalidad en la guerra tiene un significado ampliamente aceptado, que las personas racionales pueden discutir, perfeccionar y aplicar a situaciones reales. ¿Tienen razón?

Si se trata de una pregunta sobre el estado del debate filosófico sobre la moral de la guerra, la respuesta es sí. Gran parte del pensamiento occidental sobre la ética militar tiene sus raíces en Agustín, el santo escritor cristiano del norte de África cuya elaborada teoría de la 'guerra justa' ba proporcionado un marco para el debate en los 16 siglos desde su muerte. Y para los filósofos en la tradición agustiniana, la proporcionalidad es una de las cosas que usted debe considerar cuando se contempla la guerra. Otros son la probabilidad de éxito y si la guerra es un último recurso: ¿Se han probado todas las otras opciones? En este contexto, la cuestión de la proporcionalidad es juzgado por la destrucción, que bará que la guerra, sopesado en función del bien que se puede bacer.

Dicho así, la proporcionalidad es un concepto que la mayoría de los israelíes pueden vivir. Ellos argumentan que el bien que podría lograrse por la rotura de Hezbolá (y la amenaza que supone no sólo para Israel sino también para el Líbano y otros estados) no son mayores que las penurias de la población civil del Líbano.

Pero proporcionalidad en ese sentido agustiniano cubre sólo la mitad del debate moderno acerca de la fuerza militar. ¿Qué bay de boy agustinos estamos bablando es de 'jus ad bellum', es decir si es correcto estar lucbando en absoluto? Desde 1945, ba babido un nuevo énfasis en la diplomacia y la jurisprudencia, y en el idioma de los grupos de presión de los derechos bumanos, por el otro gran dilema en la ética militar: 'jus in bello', literalmente, la ley de la guerra. La cuestión aquí es la siguiente: cuna vez que las balas vuelan y que son un beligerante, como los métodos empleados y armamento es legítimo para librar su guerra? ¿Lo cuidadoso que debe ser la de proteger a los civiles y no combatientes, como los presos y beridos?

Eso es lo que los cuatro Convenios de Ginebra (ampliamente revisados en 1949, aunque nacido de un proceso que comenzó 80 años antes) y sus tres protocolos adicionales, se trata. El tribunal de crímenes de 
guerra de La Haya, que se creó para castigar las atrocidades de las guerras de los Balcanes, tiene un énfasis similar, que tiene poca competencia para considerar la causa en que se cometieron actos atroces. Y Human Rigbts Watch (HRW), un grupo con sede en Nueva York que supervisa las guerras y otros abusos en todo el mundo, es aún más contundente sobre su área de interés: conscientemente bloquea la pregunta sobre el 'jus ad bellum' $y$ concentra sus esfuerzos enteramente en 'jus in bello'.

Utilizando estos criterios estrechos, HRW bizo una extensa auditoría de las campañas encabezadas por Estados Unidos contra Serbia en 1999 y contra Irak en 2003 y encontró que en ambas ocasiones la coalición atacando violó el derecho bumanitario, al no tener suficiente cuidado para distinguir entre objetivos militares y civiles. Estos reproches no llegaron a la denuncia de las campañas en general, desde el punto de vista de HRW, que era para los demás para decidir.

Pero en el caso de Irak, en particular, se identificaron ciertos delitos específicos: el uso de bombas de racimo en áreas pobladas, y atacando las instalaciones de electricidad, tanto en la ciudad de Nasiriya, que, aunque de alguna utilidad militar, también son vitales para el bienestar civil. En otros aspectos, HRW encontró, la coalición trató muy duro para proteger a los civiles.

Una de las pruebas que los analistas de los derechos bumanos usan para bacer estos juicios es el de proporcionalidad, aunque en un sentido ligeramente diferente del que utilizan los agustinianos. Para aquellos que vigilan los derechos bumanos, una pieza clave del lenguaje es el artículo 51 del primer protocolo adicional a los Convenios de Ginebra. Este probíbe los ataques que 'se podrán prever que causarán incidentalmente muertos', que sería 'excesivos en relación con la ventaja militar concreta y directa'. Incluso en situaciones tales como el Líbano de boy, donde la mayoría de los Convenios de 1949 son técnicamente inaplicables porque Hezbolá no es un estado, el idioma de Ginebra es visto como una guía para el espíritu del derecho bumanitario consuetudinario.

El problema es que la medición de los problemas civiles contra el aumento militar es una tarea difícil, especialmente en un lugar densamente poblado como el Líbano. Por un lado, que son difíciles de separar: casi cualquier pieza de 'infraestructuras', un camino, una central eléctrica, un depósito puede ser de alguna utilidad militar, sino también ayuda a mantener viva la población civil.

Los críticos de la campaña de Israel en el Líbano (y Gaza) ban sido la elaboración de su ataque en el idioma del 'jus in bello'. De becho, HRW ya ba deplorado el uso de parte de Israel contra el personal de bombas de racimo, así como el despido de Hezbolá contra ciudades israelíes de cobetes Katyusha, armas 'sucias' que son demasiado crudo para discriminar entre soldados y civiles. El grupo de presión dice que otros aspectos de la campaña necesitan más tiempo para evaluar. Otros dicen que no bay ninguna ventaja militar que podría compensar el daño causado a los inocentes libaneses que ban sido asesinados o forzados a abandonar sus bogares en condiciones terribles y visto sus medios de vida destruidos.

De becho, no está claro, a juzgar por los últimos informes, que el ejército israelí está logrando su objetivo declarado de la eliminación de la amenaza militar de Hezbolá a la seguridad de Israel. Así que la muerte de unos 400 civiles y el desplazamiento de 800.000 de ellos tal vez ni siquiera pueden ser pesados en la 
balanza moral. Según este criterio, las acciones de Israel seguramente serán enjuiciadas desproporcionada en efecto, si no por la intención.

Sin embargo, el cálculo de la ventaja militar frente a los costos bumanos, sugirió en la fórmula Ginebra, todavía podría ser utilizados para justificar algunas de las últimas tácticas de Israel. Por ejemplo, el uso de grandes bombas para asesinar a líderes terroristas, a sabiendas de que transeúntes civiles también serán asesinados. Cuando la ganancia militar es tan grande, balcones israelies argumentan, un poco de 'ruptura de los buevos' puede ser inevitable. Eso, por supuesto, no es una comodidad a las familias en duelo de este modo.

Al final, algunos filósofos piensan, el debate sobre la ética de la guerra tendrá que reintegrar a dos preguntas: el derecho de ir a la guerra, y los métodos que se pueden usar que ban sido separados artificialmente en los tiempos modernos. Para decirlo más sencillamente, nadie va a quedar impresionado con una línea que dice: 'No comenzamos esta guerra, por lo que nuestra causa es justa, pero abora que ba comenzado, vamos a luchar tan sucio como nos gusta'. Agustín vio las cuestiones de 'jus ad bellum' $y$ 'jus in bello' como entrelazadas, y así, probablemente, debe el hombre moderno"7.

Difícil resultaría, de la multitud de textos agustinianos sobre la guerra y la paz, señalar los más relevantes, pero algunos especialistas en su filosofía presentan las consideraciones dominantes, que pueden ser esenciales en la filosofía cristiana de la paz y de la guerra:

1. El único objeto legítimo es la paz.

2. La guerra puede, sin embargo, llegar a ser necesaria, para restablecer e imponer la paz injustamente violada.

3. La guerra es, por otra parte, un desorden de tal gravedad, que se es culpable por recurrir a ella cuando el objeto legítimo puede ser honestamente alcanzado por otros medios que no sean los sangrientos.

4. En cuanto a los sufrimientos que resultan de la guerra y que afligen a veces a aquellos que tienen los mayores méritos para ser exceptuados de ellos, son cosas permitidas por Dios para fines providenciales de misericordia, de salud o de santificación ${ }^{8}$.

En el fondo, quien encontraba moralmente lícito acudir a la guerra con causa justa fue un incansable apóstol de la paz y un apologista de sus innumerables virtudes. Ahora, me permito citar el siguiente párrafo de La ciudad de Dios, el cual, posiblemente con una inspiración última en la enseñanza aristotélica de la Ética a Nicómaco, versa de la siguiente manera:

7 Traducción propia del autor, del artículo: The ethics of war. Mind those proportions. As the war in Lebanon shows, there are several ways to make a moral judgmen. En: The Economist. 29 julio 2006. sec. Middle East and Africa.

8 De la Briere, Ives, S.J. El Derecho de la Guerra Justa. México: Editorial Jus, 1944, p. 33 y ss. 
"La paz es la ordenada disposición y templanza de las partes. La paz del alma irracional, la ordenada quietud de sus apetitos. La paz del alma racional, la ordenada conformidad y concordia de la parte intelectual y activa. La paz del cuerpo y del alma, la vida melódica y la salud del viviente. La paz del hombre mortal y de Dios inmortal, la consiguiente obediencia en la fe, bajo la ley eterna. La paz de los hombres, la ordenada concordia. La paz de la casa, la conforme uniformidad que tienen mandar y obedecer los que viven juntos. La paz de la ciudad, la ordenada concordia que tienen los ciudadanos y vecinos en ordenar y obedecer. La paz de la ciudad celestial en la ordenadísima y conformísima sociedad establecida para gozar de Dios, y unir a otros en Dios. La paz de todas las cosas, la tranquilidad del orden y el orden no es otra cosa que una disposición de cosas iguales y desiguales que da a cada una su propio lugar"9.

Para un tratadista de nuestros días, el profesor belga de la Pontificia Universidad Gregoriana de Roma PAUL GiLberT S.J., la mayor confusión existente de nuestro tiempo es entre justicia y paz, y el caso colombiano, además, lo ilustró coruscantemente:

"La paz es el gran propósito nacional y enmarcarlo en las normas constitucionales que a ella se refieren, afirma que en la búsqueda de ella 'el Gobierno no tiene propósito distinto que alcanzar la paz combinando con precisión el uso legítimo de la fuerza y la vía dialogada'. Difícilmente puede encontrarse una mayor confusión intelectual alrededor de estos conceptos. Para los tratadistas, entre ellos Paul Gilbert, "la paz concebida idealmente no constituye un objetivo puro y sencillo para una vida bumana realizable. En cuanto a la justicia pensada como correctivo de la violencia, estará siempre presente en el borizonte de la vida bumana, pues si bien no se puede pensar que la violencia llegue a ser suprimida, limitarla sí tiene que ser posible (erradicarla definitivamente no, pues su origen se encuentra precisamente en la libertad de los individuos)".

Agrega el mismo autor: "en el borizonte de una vida que busca salir de la violencia, no se puede pensar que la paz o la justicia garanticen por sí mismas el final de la violencia. La paz, en efecto, no se busca para cumplir la justicia, pero en cambio la justicia sí se busca para bacer la paz. La justicia parece ser un instrumento para la paz, pero una paz protegida por la fuerza y la violencia del magistrado. La justicia constituye una condición para la paz, su instrumento privilegiado y no su adelantamiento"10.

SANTO TOMÁs completó la elaboración del derecho a la guerra, reconocido sin duda por SAN AGUSTín, con la recapitulación de los tres elementos fundamentales que hicieron clásica esa creencia. Primero, la guerra debe ser declarada por la autoridad competente; segundo, debe existir una causa justa, y tercero, la intención de ir a la guerra debe ser recta.

Los dos últimos elementos enunciados son aquellos que, en las situaciones concretas de los últimos siglos, han permitido recurrir al arsenal ideológico de SAN AGUSTíN para declarar la licitud o ilicitud de una guerra. En el primer caso, se trata de que exista o no una guerra en la cual el Estado tiene el derecho de resistir por medio de las armas en nombre del bien público y de la comunidad injustamente herida. Trátese en el fondo de la vigencia de la justicia vindicativa y, de allí, la unión que SANTO TOMÁs hace entre

9 SAN Agustín. La ciudad de Dios. XIX, XIII 1.

10 Tomado de: Copello Faccini, Antonio (ed.). Violencia, justicia y olvido. Bogotá D.C.: Fundación Universidad de Bogotá Jorge Tadeo Lozano, 2008, p. 106. 
la guerra justa y la falta imputable y culpable. Finalmente, la intención recta se podría llamar la "causa final", la cual se encuentra sometida a la moral, ya que los demás deberes de caridad, justicia, prudencia y temperancia no pierden nunca su valor obligatorio, cada uno en su lugar respectivo. El mismo SAN AGUSTín, que vivió en una época que no puede considerarse pacífica, contribuyó a la teoría de la paz y puso en duda que existiera alguien que no la quisiera; pero, por otro lado, admitió la necesidad de la guerra.

Con todo, el gran metafísico y jurista granadino FrAnCISCO SuÁrEZ S.J. ${ }^{11}$ fue explícito en desarrollarlo cabalmente:

"El derecho a la guerra nace por lo tanto del que tiene una república ofendida a reparar la injusticia que se le ba becho. Reconocer de plano que es acomodado a la naturaleza y justo puede parecer cruel pero es bumano y lógico. Sería mejor que no bubiera guerras, pero mientras naciones que no respetan el derecho bumano un pacifismo a ultranza solo aprovecharía a los malvados. No se puede prescribir por completo la guerra, como no se puede dejar de castigar a los malhechores, lo que es necesario es ponerla inexorablemente al servicio de la justicia"12.

Por amor a la paz y a la justicia, que la guerra ha de conservar o restaurar, SuÁREZ establece las siguientes condiciones:

1. La guerra, de suyo, no es intrínsecamente mala ni probibida a los cristianos.

2. La guerra defensiva no solo es lícita, sino que a veces está mandada, porque el derecho de propia defensa es natural y necesario.

3. La misma guerra ofensiva no es mala de suyo, sino que puede ser bonesta y necesaria, porque con frecuencia es necesaria la república para repeler las ofensas y coaccionar a los enemigos.

4. Para que se haga la guerra lícitamente, deben observarse tres condiciones: ser becha por el poder legítimo, que tenga una justa causa y que se guarde la debida moderación y equidad en su principio, en su prosecución y en su victoria.

Como lo había vaticinado SAmuEl HunTington, en su libro sobre los grandes conflictos del siglo XXI, que están ligados a la violencia de origen religioso (¡quién lo creyera!) $\mathrm{y}$ al terrorismo que ha azotado igualmente a las naciones desarrolladas y a los pueblos pobres. En los últimos años, y como recrudecimiento de esa violencia, el conflicto en Siria ha sido causa eficiente de mucha sangre, dolor, destrucción y lágrimas. En ese contexto, y frente a sucesos como los de Niza, Bruselas y París, el martirio de un anciano sacerdote que en su bondad evoca al santo cura de Ars, forma un conjunto de hechos y circunstancias que han horrorizado al mundo. Pretender, como la Conferencia de Roma, que llevó al papa FRANCISCO a decir, en el vuelo que lo condujo a Cracovia, que estamos en plena guerra, y si esto es cierto, olvidarse de la vigencia de la guerra justa es

12 Véase: Gallegos, José María. La doctrina política del padre FranCisCo SuÁreZ. México: Editorial Jus. 
un despropósito de incalculables proporciones. En nombre de un pacifismo a ultranza, que ya innumerables tragedias causó en el pasado, y un amargo recuerdo de la Segunda Guerra Mundial, cuando se invocó pensando que constituiría un freno al nazismo y a las desorbitadas ambiciones del Nacional Socialismo alemán, es un error gigantesco en la actual situación de las relaciones internacionales, es descabellado, carente de justificación y no constituye además un estímulo para alcanzar la paz.

Considero útil, para la mejor inteligencia del tema que nos ocupa en estas reflexiones, transcribir el epílogo de un opúsculo publicado en el año 2008 sobre "Violencia, justicia y paz", donde, sin apartarnos de la vigencia y utilidad de la guerra, se dan las circunstancias exigidas por la doctrina dominante para presentar las dificultades inherentes a esta posición.

"Fue el genio de san Agustín el autor de la teoría bien conocida en el derecho internacional de la 'guerra justa', estructurada en la Edad Media por santo Tomás y perfeccionada por los autores de la escuela clásica española del derecho de gentes, en el siglo XVI, particularmente Francisco de Vitoria y Francisco Suárez, como recuerda uno de sus más recientes biógrafos ${ }^{13}$. Agustín murió bace más de 1.600 años y desde su muerte basta boy no ba babido período en la bistoria en el cual sus libros no sean leídos, admirados, controvertidos y editados en todos los continentes y en muchos idiomas. Su figura volvió a ser mencionada con ocasión de la guerra de Irak en todo el mundo.

Cuatro consideraciones dominantes se destacan en la filosofía de la paz y de la guerra según Agustín:

1) El único objeto legítimo es la paz;

2) La guerra puede, sin embargo, llegar a ser necesaria para restablecer e imponer la paz injustamente violada

3) La guerra es un desorden de tal gravedad, que se es culpable por acudir a ella cuando el objeto legítimo puede ser bonestamente alcanzado por otros medios que no sean los sangrientos,

4) En cuanto a los sufrimientos que resultan de la guerra y que afligen a aquellos que tienen los mayores méritos para exceptuarlos de ella puede adquirir la connotación de injusta.

Durante las semanas que antecedieron a la decisión del presidente George W. Busb de ir a la guerra, estos principios fueron recordados con idénticas claridad y vehemencia por el expresidente de los Estados Unidos Jimmy Carter y por Juan Pablo II, quien en uno de sus últimos pronunciamientos públicos, antes de iniciarse las acciones militares, no vaciló en afirmar que 'quienes por sí y ante sí deciden que se ban agotado los medios pacíficos que el derecho internacional ba establecido para la solución pacifica de los conflictos entre Estados soberanos asumen una gravísima responsabilidad, ante Dios, ante su conciencia y ante la bistoria', para conchuir que de acuerdo con la doctrina dominante no se daban las condiciones para una guerra justa.

El expresidente Carter fue claro al respecto y en artículo publicado en el New York Times el 10 de marzo de 2003, escribió: 
1) La guerra, para ser justa, debe considerarse como el último recurso después de baberse agotado todas las acciones no violentas. En el caso de Irak es obvio que bay claras alternativas a una guerra propuesta por líderes de Estados Unidos y presentadas al Consejo de Seguridad.

2) La distinción entre combatientes y no combatientes nos lleva a temer que bombardeos aéreos indiscriminados, así se alegue un cierto grado de certeza, en la escogencia de objetivos militares cercanos a bospitales, escuelas, mezquitas, lleva un peligro colateral admitido por el comandante de las fuerzas americanas en la región, Tommy Franks.

3) La violencia usada debe ser proporcional a la injuria sufrida por los Estados Unidos; a pesar de los abominables crímenes de Saddam Hussein, los Estados Unidos no ban podido demostrar la participación de Irak en la tragedia del 11 de septiembre.

4) La autoridad legítima para declarar la guerra y eliminar las armas de destrucción de Irak, descansa unicamente en el Consejo de Seguridad de las Naciones Unidas y los propósitos americanos para establecer en la región una 'Pax Americana' carecen de legitimidad porque, no disponen de la autoridad legítima para bacerlo.

Consecuencia directa de la decisión del presidente Busb de iniciar este conflicto, que en el momento de escribir estas páginas tiene más de un lustro de dolor, muerte y destrucción, fue la revisión por muchos tratadistas de derecho internacional, de relaciones internacionales y de ética sobre la inmensa dificultad de estructurar en la circunstancia del mundo globalizado la causa justa para una guerra, diferente de la defensiva o de aquellas autorizadas por los órganos competentes de las Naciones Unidas.

No se trata de llegar a un pacifismo a ultranza, como bien lo explicó Hans Kung en sus conferencias de Bogotá, durante su inolvidable visita de 2007, no sin antes dejar salvaguardado el principio de la soberanía jurídica en este campo:

La libre adhesión a una ética común ba de ser apoyada sin duda por el derecho que en determinadas circunstancias puede ser reclamado judicialmente, en caso de genocidio, crímenes de bumanidad, crimenes de guerra y agresión lesiva del derecho internacional y en la actualidad recurriendo incluso al Tribunal Internacional Penal de La Haya en caso de que un Estado firmante del tratado no pueda o no quiera perseguir judicialmente los crímenes ocurridos en su territorio o perpetrados por sus soldados o sus autoridades ${ }^{14}$.

El profesor James Turner Jobnson, de la Universidad de Rutgers, en su trabajo sobre la Causa Justa presentado al coloquio sobre 'El pensamiento católico y la política mundial en el siglo XXI', celebrado en Roma el 29 de abril de 2004 en la Universidad Gregoriana, aludió a diversos cambios que, con posterioridad a la guerra de Irak, parecen abrirse camino para restringir la aplicación del concepto de la guerra justa y agregar a la idea de la soberanía nacional un elemento moral que permita establecer un marco de acción para distinguir los distintos casos que puedan presentarse y aludía a los elementos que en la teoría tradicional se ban presentado para justificar una acción bélica: recuperación de lo que injustamente se ba perdido, castigo del mal ocasionado y defensa del bien común.

No se oculta a los estudiosos que, frente a la realidad de la guerra, que indiscriminada y desproporcionadamente, puede causar destrucción, existe una presunción contra el recurso a la misma, a la cual aludía

14 Kung, Hans. Ética mundial en América Latina. Madrid: Trotta, 2008, p. 49 y 50. 
Juan Pablo II en su intervención del Angelus en la Plaza de San Pedro el 16 de marzo de 2003, cuando en las Azores se reunieron los jefes de Estado de Estados Unidos, Gran Bretaña, España y Portugal, tres días antes de iniciar el conflicto:

Quisiera recordar a los países miembros de las Naciones Unidas y en particular a los integrantes del Consejo de Seguridad que el uso de la fuerza representa el último recurso, después de baberse agotado todos los medios pacíficos existentes y de acuerdo con los conocidos principios de la Carta de San Francisco. Debo decir: todavía bay tiempo para negociar, todavía bay tiempo para la paz; nunca es demasiado tarde para llegar a un entendimiento y continuar las discusiones y comprometerse en negociaciones que no signifiquen bumillación sino búsqueda de la paz. La fuerza es un último recurso y debe tener en cuenta la responsabilidad de la bumanidad para encontrar la paz universal. A través de los medios que la política y la educación ofrecen, la comunidad internacional debe promover el respeto de los derechos bumanos y consecuencialmente la lucba contra el terrorismo no debe limitarse solamente a medidas de represión y a operaciones bélicas.

Quiera la Providencia iluminar a los gobernantes del mundo para escoger una ruta diferente, cuando se presenten las inevitables diferencias entre Estados soberanos y evitar así que el siglo recién comenzado se transforme en una centuria más de guerra y violencia"15.

De ese momento a hoy, se ha avanzado con inusitada velocidad, y la conferencia celebrada en Roma adoptó una posición francamente insostenible para muchos católicos, estudiosos del tema y observadores internacionales. Un principio de filosofía y de ética de san AGustín: en las cosas necesarias, unidad; en las cosas discutibles, libertad, y en todas, caridad nos permite, sin vacilaciones, apartarnos de aquella, no obstante el entusiasmo manifestado por muchos estudiosos del tema al analizar las conclusiones de la Conferencia de Roma.

Finalmente, nada más iluminante que este párrafo del papa MONTINI sobre la naturaleza de la paz que todos anhelamos: "Cuando bablamos de la paz no proponemos un inmovilismo mortificante y egoista, la paz no se goza, se crea. La paz no es un nivel normal alcanzado, es un nivel superior al cual todos debemos aspirar siempre. No es una ideología soporifera, es una concepción deontológica, que obliga a todos los responsables del bien común a ofrecer un esfuerzo para esta causa, que es la causa verdadera de la bumanidad. Estamos conscientes de la paradoja implícita en este programa que parecería fuera de la realidad filosófica, social, bistórica. La lucba es la ley. La lucba es la fuerza del éxito y también es la justicia; que la lucha puede conseguir éxito nadie lo pone en duda, pero sí que ella llegue a constituir la idea luz. Es tiempo de que la civilización se inspire en una concepción diferente de aquella lucha, de aquella violencia, de aquella guerra, y que el mundo camine bacia un justicia verdadera y universal"16.

No es superfluo concluir este escrito con algunas reflexiones, a partir de la advertencia del papa FRANCISCO sobre el problema de la violencia generalizada, la guerra atroz en muchos lugares del mundo, particularmente en Siria, y el anhelo de una paz insatisfecha.

15 Copello Faccini, AnTOnio. Violencia, justicia y olvido. Epílogo. Bogotá D.C.: Fundación Universidad de Bogotá Jorge Tadeo Lozano, 2008, pp. 111-115.

16 Martini, Carlo Maria. Il riposo della Colomba, contributi per una pace possibile. Milán: San Paolo, 1994, p. 29 y ss 
Esta situación había sido vaticinada por SAMUEL HuNTINGTON, en su famoso libro The clasb of civilization and the remarking of world order, donde subrayó que los más importantes y peligrosos conflictos del siglo XXI no serían entre grupos sociales, ricos o pobres, u otros claramente definidos, sino entre personas oriundas de diferentes civilizaciones. No es el lugar para entrar en el desarrollo de la tesis y de la síntesis, pero, ciertamente, la experiencia ya vivida en lo que va corrido del siglo XXI así lo indica.

Michael Mandelboum, en su libro publicado hace pocos meses, y que ThOmas FrieDMAN, el insuperable comentarista internacional del New York Times vaticinó sería el libro del año, Fracaso de una misión: América y el mundo en la era de la post guerra fría, encuentra que hay cuatro períodos en la política exterior americana claramente identificados, y que sirven de contexto histórico para juzgarla.

1. El primer período, que comienza con la presidencia de GEORGE WASHINGTON, en 1989, y la guerra con España, y que se caracteriza por ser uno de aislamiento y desarrollo de la naciente economía.

2. Entre 1898 y 1945, los Estados Unidos se lanzaron a la arena internacional, como uno entre muchos poderes, y se vieron envueltos en las dos grandes conflagraciones mundiales del siglo XX, uniéndose a la coalición victoriosa en la primera y como líder de la alianza triunfante en la segunda.

3. Entre 1945 y el final de la Guerra Fría, fueron una de las dos grandes potencias en el mundo bipolar de entonces, y garantizaron la seguridad y el orden del mundo occidental durante un largo período, así estuviera fundado, como lady THATCHER lo dijo alguna vez, en "el imperio de la paz nuclear".

4. En el 2014, año terminal de un largo período, permitió a las naciones victoriosas celebrar el centenario de la Primera Guerra Mundial y el surgimiento de la paz, pero también el gran cambio en la política exterior americana, cuyo énfasis fue contribuir a la transformación de la política y la economía en muchas naciones, con una relativa prescindencia de la defensa y seguridad americana, emprendidas con mayor énfasis en China y Rusia, pero en menor escala en Somalia, Haití, Bosnia, Kosovo, Afganistán, Irak y Medio Oriente.

Este objetivo terminó siendo, como el autor lo presenta, un fracaso cuyo análisis es uno de los objetivos del libro, y contribuyó a socavar el nuevo orden internacional, establecido por el primer presidente BuSH, fundado sobre la globalización de la economía que, en el fondo, al generar mejores resultados, redujo las competencias en gastos militares y de seguridad, la imitación en el uso y la posesión de armas nucleares y la creencia que tanto China como Rusia limitarían sus políticas para acomodarse a ese nuevo objetivo. Al final de este año, se veían apenas los escombros del nuevo orden mundial, y los Estados Unidos no tuvieron alternativa diferente a la de volver al uso del poder, para la defensa de sus intereses.

Todo finalmente cambió con los trágicos sucesos de septiembre 11 en Nueva York, de los cuales acaban de conmemorarse 15 años, y la crisis financiera que lo antecedió con 
la bancarrota de Lehman Brothers, que afectaron la estructura de gobierno americano, el funcionamiento de la economía globalizada, la confianza de inversionistas y gobiernos y el orden internacional, en el cual la administración americana había fincado sus mejores esperanzas. Para entonces, China, Rusia, Corea del Norte e Irán habían llegado a ser un obstáculo formidable para la política americana de presencia de sus propios valores allende sus fronteras y regresar a la tarea de su propia autodefensa.

La violencia, la guerra y la violación del Derecho Internacional Humanitario y sus principios esenciales, con la invasión de Ucrania y el renacimiento del totalitarismo ruso, que han caracterizado a un mundo globalizado, pero amenazado por el odio y la lucha. París, Bruselas, Niza son símbolos de lo vivido en los últimos años, cuando el vaticinio del autor ya citado se convirtió en espantosa realidad. Si el mundo vive hoy la guerra y la violencia, muchos creemos que no es posible, en ese contexto internacional, enterrar dieciséis siglos de historia y la posibilidad, no obstante las dificultades en la aplicación de los principios tutelares de una guerra justa, de renunciar a ella cuando los epígonos de la violencia buscan destruir el orden jurídico internacional.

Con la autoridad universalmente reconocida de uno de los grandes filósofos de la historia en el siglo XX, ArnOld TOYnBeE, concluida la Segunda Guerra Mundial y en plena vigencia de la Guerra Fría, juzgaba erróneo el pacifismo a ultranza latente en la conferencia de Roma: "el peligro más evidente que bay en la estrategia del pacifismo reside en la manera como los pacifistas se enfrentan al becho de que en la misma medida en que su acción resulta eficaz, el primer efecto podría ser el de colocar a los estados en los cuales el pacifismo tenga una fuerza política apreciablemente poderosa a merced, en los estados en que son impotentes; lo que equivaldría a permitir que los más inescrupulosos gobiernos, las más tenebrosas potencias militares se biciesen dueños del mundo en el primer capítulo del drama.

Enfrentarse con ese problema y atenerse a sus consecuencias inmediatas presupone una activa perspicacia y un beroísmo pasivo que ban sido exbibidos por los santos, pero nunca por el bombre corriente de la masa. Ciertamente a menudo los pueblos se ban sometido en masa al dolor y al agravio de ser oprimidos por conquistadores que en el cotejo con sus víctimas fueron brutales y bárbaros. En 1940 el mundo estuvo a punto de aceptar la dominación de una Alemania controlada por los nazis e inspirada por el espiritu satánico de Hitler pero apenas tenemos que recordar el ánimo que prevalecía en Francia y Gran Bretaña durante los años de apaciguamiento y más tarde en Francia en la época de Vichy, para que se comprenda la verdad que entre los motivos que inspiran la negativa en masa a resistir a la agresión militar con la fuerza de las armas en defensa propia el generoso borror del santo ante el pecado de la guerra cuenta mucho menos que la natural y ordinaria aversión del mortal a pagar el borrendo precio de sangre y lágrimas que la guerra impone"17.

El pasado 20 de septiembre, y con el idílico paisaje de la Toscana como marco hermoso, se reunieron en Asís, convocados por el papa FRANCISCO, líderes internacionales y religiosos, para conmemorar el trigésimo aniversario de la primera vigilia de oración en Asís, organizada y convocada por JUAN PABLO II, y buscar el renacimiento de la paz en tantos lugares del mundo. No se puede afirmar que recurrir a la guerra justa, con las 
limitaciones y exigencia que ello impone, sea una violación de los principios internacionales ${ }_{i}$ por el contrario, demuestra que la humanidad se ha visto obligada a recurrir a ella para preservar la paz y la vigencia de los valores exigida por la dignidad de la persona humana. Pero enterrarla en los momentos en que hay un contexto internacional de guerra, violencia y desconocimiento del Derecho Internacional sería un trágico error que los asistentes a la conmovedora plegaria de Asís dudo cometerían.

Lo anterior no es óbice para desconocer el sublime anhelo del papa FRANCISCO por alcanzar la paz universal y silenciar las armas. Pero de la misma manera que el derecho penal juzga y condena conductas delictuosas, la guerra puede ser el último instrumento para la defensa colectiva, agotando todos los medios que el derecho y las sanas costumbres internacionales ofrecen para mediar en una situación de crisis y peligro.

BIBLIOGRAFÍA

Copello Faccini, ANTONiO (ed.). Violencia, justicia y olvido. Bogotá D.C.: Fundación Universidad de Bogotá Jorge Tadeo Lozano, 2008.

De la Briere, Ives, S.J. El Derecho de la Guerra Justa. México: Editorial Jus, 1944.

De Roux, Francisco, S.J. Columna semanal de El Tiempo, 4 de mayo de 2017.

Guerra y civilización. Buenos Aires, 1952.

KunG, Hans. Ética mundial en América Latina. Madrid: Trotta, 2008.

LAFAYE, JACQUES. Mesías, cruzadas, utopías: el judeo-cristianismo en las sociedades iberoamericanas.

2. a ed. Fondo de Cultura Económica, 1997.

Martini, Carlo Maria. Il riposo della Colomba, contributi per una pace possibile. Milán: San Paolo, 1994.

O'Donnell, James. Augustine. Nueva York: Harper Collins, 2005

San Agustín. La ciudad de Dios, XIX, XIII 1.

SuÁreZ, Francisco. José María Gallegos. México: Editorial Jus. 